BRAVILLIAN JOURNAL

www.bjournal.com.br
ISSN 0100-879X

Volume 44 (8) 729-813 August 2011

BIOMEDICAL SCIENCES

AND

CLINICAL INVESTIGATION

Braz J Med Biol Res, August 2011, Volume 44(8) 778-785

doi: 10.1590/S0100-879X2011007500085

Sildenafil prevents the increase of extravascular lung water and pulmonary hypertension after meconium aspiration in newborn piglets

F.E. Silvera, M.F. Blasina, L. Vaamonde, S. Tellechea, C. Godoy, S. Zabala, G. Mañana, M. Martell and W. Olivera

The Brazilian Journal of Medical and Biological Research is partially financed by
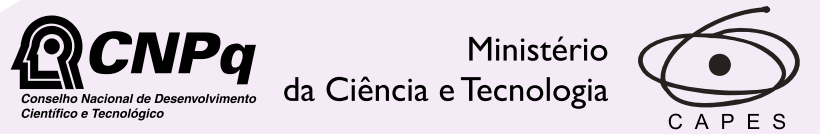

Ministério da Educação
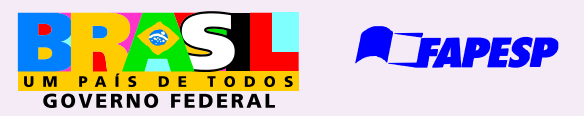

Institutional Sponsors
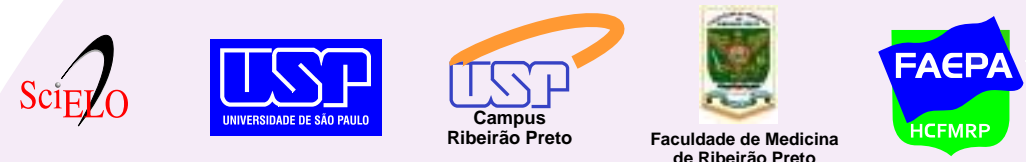

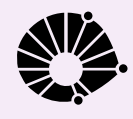

UNICAMP
Ф SHIMADZU

Explore High - Performance MS Orbitrap Technology In Proteomics \& Metabolomics

$\underset{\text { analitica }}{\text { analiticaweb.com.br }}$ SCIENTIFIC 


\title{
Sildenafil prevents the increase of extravascular lung water and pulmonary hypertension after meconium aspiration in newborn piglets
}

\author{
F.E. Silvera ${ }^{1 *}$, M.F. Blasina ${ }^{1,4 *}$, L. Vaamonde ${ }^{1,4 *}$, S. Tellechea ${ }^{1}$, C. Godoy ${ }^{1}$, \\ S. Zabala ${ }^{1}$, G. Mañana ${ }^{2}$, M. Martell ${ }^{1}$ and W. Olivera ${ }^{3}$ \\ ${ }^{1}$ Departmento de Neonatología, Área Básica, ${ }^{2}$ Departmento de Anatomía Patológica, \\ ${ }^{3}$ Departmento de Medicina Crítica, Hospital de Clínicas, Montevideo, Uruguay \\ ${ }^{4}$ Departmento de Neuroquímica, Instituto de Investigaciones Biológicas Clemente Estable, Montevideo, Uruguay
}

\begin{abstract}
Meconium aspiration syndrome causes respiratory failure after birth and in vivo monitoring of pulmonary edema is difficult. The objective of the present study was to assess hemodynamic changes and edema measured by transcardiopulmonary thermodilution in low weight newborn piglets. Additionally, the effect of early administration of sildenafil $(2 \mathrm{mg} / \mathrm{kg} \mathrm{vo}, 30 \mathrm{~min}$ after meconium aspiration) on this critical parameter was determined in the meconium aspiration syndrome model. Thirty-eight mechanically ventilated anesthetized male piglets (Sus scrofa domestica) aged 12 to $72 \mathrm{~h}$ (1660 $\pm 192 \mathrm{~g}$ ) received diluted fresh human meconium in the airway in order to evoke pulmonary hypertension (PHT). Extravascular lung water was measured in vivo with a PiCCO monitor and ex vivo by the gravimetric method, resulting in an overestimate of $3.5 \pm 2.3 \mathrm{~mL}$ compared to the first measurement. A significant PHT of 15 Torr above basal pressure was observed, similar to that of severely affected humans, leading to an increase in ventilatory support. The vascular permeability index increased $57 \%$, suggesting altered alveolocapillary membrane permeability. Histology revealed tissue vessel congestion and nonspecific chemical pneumonitis. A group of animals received sildenafil, which prevented the development of PHT and lung edema, as evaluated by in vivo monitoring. In summary, the transcardiopulmonary thermodilution method is a reliable tool for monitoring critical newborn changes, offering the opportunity to experimentally explore putative therapeutics in vivo. Sildenafil could be employed to prevent PHT and edema if used in the first stages of development of the disease.
\end{abstract}

Key words: Lung water; Meconium aspiration syndrome; Newborn; Sildenafil; Pulmonary hypertension

\section{Introduction}

Meconium aspiration syndrome (MAS) in newborns leads to acute respiratory failure with a mortality of up to $10 \%$ (1). Meconium components cause airway obstruction, chemical pneumonitis, surfactant inactivation, complement activation, pulmonary vasoconstriction (2), and pulmonary edema (3) affecting gas exchange.

In MAS, the increase in extravascular lung water (EVLW) has not been monitored in clinical situations. Lung water (LW) was estimated by clinical evaluation, chest radiograph or blood gas determinations (4-6). The possibility of in vivo EVLW monitoring is relevant since most published data have reported ex vivo measurements without any information about the first hours of development of this pathological condition. During recent years, technical advances have provided the opportunity of measuring EVLW in vivo in order to improve knowledge about this disorder. One of these devices is the PiCCO monitor, which utilizes a thermal indicator to measure the amount of EVLW and the hemodynamic status. This technology, currently used for adult monitoring, has still limited application in pediatric/newborn patients because of the lack of experience (7).

Furthermore, the use of drugs for reducing pulmonary hypertension (PHT) has been increasing in the last decade, since nitric oxide, the gold standard treatment, is expensive and not available at all hospitals or in all countries. Sildenafil, a phosphodiesterase- 5 inhibitor, has proved to be effective

Correspondence: M.F. Blasina, Departmento de Neonatología, Hospital de Clínicas, Av. Italia s/n, entre Las Heras y Avda. Ricaldoni, P.O. Box 11600, Montevideo, Uruguay. E-mail: fblasina@iibce.edu.uy

*These authors contributed equally to this study.

Received November 9, 2010. Accepted June 15, 2011. Available online July 8, 2011. Published August 19, 2011. 
for treating PHT in newborns $(8,9)$, but its effectiveness in alleviating other changes that occurr during MAS has not been studied.

In this context, the use of a transcardiopulmonary thermodilution (tt) device during MAS in small newborn babies would be useful for in vivo evaluation of EVLW and hemodynamic monitoring. Three questions were addressed: Does the device adequately measure the EVLW in small newborns? In this case, does MAS increase EVLW in newborn piglets? Is the administration of sildenafil useful in the early treatment of meconium aspiration? The specific aim of this study was to monitor EVLW and hemodynamics after meconium aspiration in newborn piglets, exploring the utility of the in vivo monitoring of newborn acute respiratory failure and to evaluate the hemodynamic response after the oral administration of sildenafil, as it is usually administered to newborn babies. To address these questions, the validation of the thermodilution method in animals weighing 1300 to $2700 \mathrm{~g}$ was required since it has not been reported previously (10).

\section{Material and Methods}

\section{Animals}

The study was conducted according to the ethical principles that regulate animal research issued by the Helsinki Declaration, the American Physiological Society, and the Uruguayan Institutional Animal Care and Use Committee (CHEA) of the University of the Republic, authorization No. 071140-001741-06 (http//www.expe.edu.uy/expe/srchsite Resoluciones.nsf/multidataBaseSearch_Resol).

Term newborn piglets (Sus scrofa domestica) between 12 and $72 \mathrm{~h}$ of life (to assure no ductus communication as reported by Haworth and Hislop, 11) were obtained from a local farm.

\section{Study design}

Does the PiCCO accurately measure the EVLW parameter? The validation of EVLW measurement by the thermodilution method using a single thermal indicator was performed in 9 animals (weighing: $1380 \pm 170 \mathrm{~g}$ ) to compare the in vivo measure of EVLW with the ex vivo LW determination.

Does MAS increase EVLW in newborn piglets? The MAS study group consisted of 19 anesthetized and paralyzed pigs $(1752 \pm 228 \mathrm{~g})$ ventilated throughout the experiment in the supine position, with a tidal volume of $6 \mathrm{~mL} / \mathrm{kg}$, respiratory rate $(\mathrm{RF})$ of 15 breaths/min, positive end-expiratory pressure (PEEP) of $5 \mathrm{cmH}_{2} \mathrm{O}$, and variable oxygen inspired fraction $\left(\mathrm{FiO}_{2}\right)$, beginning with 0.21 (adjusting it for a blood oxygen saturation $\left(\mathrm{SatO}_{2}\right)$ higher than $\left.90 \%\right)$. Animals were fully instrumented for hemodynamic monitoring (systemic and pulmonary pressure).

Is administration of sildenafil useful in the early treatment of meconium aspiration? Sildenafil, $2 \mathrm{mg} / \mathrm{kg}$, was adminis- tered orally to 10 anesthetized and paralyzed pigs $30 \mathrm{~min}$ after MAS (1665 $\pm 176 \mathrm{~g})$, with the rest of the experiment being the same as in the previous group.

\section{Experimental protocol}

The animals were studied under three conditions in which a complete set of hemodynamic, respiratory mechanics and gas exchange data were collected: 1) baseline in healthy lung. Measurements were taken 30 min after instrumentation of the animal. 2) Aspiration of meconium in the airway. Measurements were taken 60 min later and repeated every $30 \mathrm{~min}$, until the end of the experiment - up to $120 \mathrm{~min}$. 3) Measurements were taken after aspiration of physiological solution in the control group. 4) Thirty minutes after aspiration of meconium in the airway, sildenafil was administered orally and measurements were taken every $30 \mathrm{~min}$, until the end of the experiment 120 min later.

\section{General procedures}

Anesthesia was induced with $50 \mathrm{mg} / \mathrm{kg}$ ketamine $\mathrm{im}$ and by a peripheral venous access with a push of $0.3 \mathrm{mg} / \mathrm{kg}$ midazolam iv, $10 \mu \mathrm{g} / \mathrm{kg}$ fentanyl iv and $2.5 \mathrm{mg} / \mathrm{kg}$ propofol $i v$, and maintained with $3 \mathrm{mg} \cdot \mathrm{kg}^{-1} \cdot \mathrm{h}^{-1}$ propofol throughout the experiment. Five percent dextrose infusion $\left(60 \mathrm{~mL} \cdot \mathrm{kg}^{-1} \cdot \mathrm{day}^{-1}\right)$ was the basal fluid and glucose administration.

Access to the airway tract was achieved by tracheotomy in order to assure no meconium leak. Mechanical ventilation was performed with a Sechrist IV 200 ventilator (Sechrist Industries Inc., USA). Initial ventilatory parameters were RF 20 cycles/min, $4 \mathrm{cmH}_{2} \mathrm{O}$ PEEP, $20 \mathrm{cmH}_{2} \mathrm{O}$ maximum inspiratory pressure (MIP), 0.3 inspiratory time, and $\mathrm{FiO}_{2}$ of 0.21 . PEEP was not modified during the experiments.

$\mathrm{SatO}_{2}$ and electrocardiogram with $\mathrm{D} 2$ lead recording were monitored while systemic and pulmonary pressures were invasively monitored with intravascular catheters and recorded on an enGuard CM4 monitor (Masimo SET, Ohmeda Medical, IVY Biomedical System Inc., USA) connected to a computer for digitalizing data (Windaq Software).

APiCCO 4 French 12-cm thermo-sensible catheter was accessed to the abdominal aorta through the femoral artery in order to continuously monitor the central body temperature and systemic arterial pressure (SAP), and to sample arterial blood for gas determinations and for the measurement of cardiac output (CO) and EVLW by thermo-dilution (PiCCO ${ }^{\circledR}$ classic, Pulsion Medical Systems, Germany). Each $\mathrm{CO}$ and EVLW determination was repeated three times by the injection of $2 \mathrm{~mL}$ cold saline (independently of the respiratory cycle) into the right atrium through a superior vena cava catheter.

Left anterior thoracotomy was performed to place a 20-gauge Teflon catheter in the pulmonary artery trunk through the right ventricular wall, with the position being determined by the typical waves of the pulmonary arterial pressure (PAP). Infection prophylaxis was performed with cephradine 50 and gentamicin $4.5 \mathrm{mg} \cdot \mathrm{kg}^{-1} \cdot \mathrm{dose}^{-1}$ 
administered once by peripheral venous access previous to surgical manipulations.

Central body temperature was maintained $\left(38.5^{\circ}\right.$ $39.5^{\circ} \mathrm{C}$ ) with a heater under a plastic cover (Thermacare, Gaymar Industries, USA).

The procedure was completed within $1 \mathrm{~h}$ and the stabilization period was considered to be complete when: 1) heart rate $(\mathrm{HR})$ and SAP variability were within $10 \%$ of the pre-thoracotomy values, and 2) $\mathrm{PO}_{2}$ was 75 to $100 \mathrm{mmHg}$, $\mathrm{PaCO}_{2} 35$ to $45 \mathrm{mmHg}$, and $\mathrm{pH} 7.35$ to 7.45 .

By means of a mathematical analysis of the thermodilution blood curve plus the simultaneous intra-arterial pressure determinations, the PiCCO can calculate the following variables, as previously reported (12) - EVLW: mL/ $\mathrm{kg}$; global end-diastolic volume (GEDV): $\mathrm{mL}$; intra-thoracic blood volume (ITBV): $\mathrm{mL}$; systemic vascular resistance index (SVRI): dyn $\cdot \mathrm{S}^{-1} \cdot \mathrm{cm}^{-5} \cdot \mathrm{m}^{(2)-1}$; stroke volume index (SVI): $\mathrm{mL} / \mathrm{m}^{2}$; cardiac index $(\mathrm{Cl}): \mathrm{L} \cdot \mathrm{min}^{-1} \cdot \mathrm{m}^{(2)-1}$; ITBV index: $\mathrm{mL} / \mathrm{m}^{2}$; extravascular lung water index (ELWI): $\mathrm{mL} /$ $\mathrm{kg}$. Additionally, the pulmonary blood volume (PBV) and the vascular permeability index (VPI) were calculated by the following formulas - PBV: $\mathrm{mL}=$ ITBV-GEDV; VPI = EVLW/PBV; pulmonary vascular resistance index $(P V R I)=$ $\mathrm{dyn} \cdot \mathrm{s}^{-1} \cdot \mathrm{cm}^{-5} \cdot \mathrm{m}^{(2)-1}=\mathrm{PAP} / \mathrm{Cl}$.

\section{Meconium aspiration procedure and sildenafil treatment}

After the stabilization period, filtered fresh meconium was diluted in $20 \%$ physiological saline and administered into the airway $(2 \mathrm{~mL} / \mathrm{kg}$ three times reaching a total dose of $6 \mathrm{~mL} / \mathrm{kg}$ ) with a swinging thoracic movement to assure homogeneous distribution. The PAP increased, reaching a long-lasting plateau at $60 \mathrm{~min}$, with this time being the beginning of the pathological response (post-meconium) due to the stability of the hemodynamic measures after the next $60 \mathrm{~min}$. The last group of variables was determined $15 \mathrm{~min}$ before euthanasia.

In the group of animals treated with sildenafil, the drug was administered orally with a probe 30 min after the end of the administration of meconium, dissolved in $5 \%$ dextrose solution, at a dose of $2 \mathrm{mg} / \mathrm{kg}$. The time of administration was defined with the intention of exploring the capacity of the drug to modulate the response immediately after meconium aspiration, and the evaluation of the response was based primarily on two critical parameters, PAP and LW.

\section{Determination of lung water ex vivo}

Euthanasia was performed by intravenous $\mathrm{KCl}$. Lungs were extracted while maintaining a $25 \mathrm{cmH}_{2} \mathrm{O}$ positive airway pressure by tracheal occlusion. Excised lungs were weighed and lyophilized for $24 \mathrm{~h}$. In the group of animals for validation of thermodilution measures, LW content was calculated as the difference between wet and dry lung weight.

\section{Histological analysis}

A group of 4 control and 5 post-meconium lungs were fixed in $20 \%$ paraformaldehyde and hematoxylin-eosinstained sections were analyzed by a pathologist by light microscopy.

\section{Statistical analysis}

The EVLW measurement by the PiCCO thermodilution method in animals weighing 1300 to $2700 \mathrm{~g}$ was validated by Bland-Altman analysis.

The results obtained from the MAS experimental study were analyzed by ANOVA and by the Student $t$-post-test. $P<0.05$ and $P<0.01$ were considered to be significant. Data are reported as means \pm SD.

\section{Results}

\section{In vivo EVLW vs ex vivo LW content}

Comparison between the last in vivo EVLW assessed by the thermodilution method and the LW content in lyophilized lungs showed a statistically significant correlation in piglets weighing 1300 to $2100 \mathrm{~g}$ with $r=0.95$, and Bland Altman analysis with a $95 \%$ confidence interval yielded a result of $0.3 \pm 1.7 \mathrm{~mL}$. As shown in Figure 1A, the EVLW content post-meconium determined by the in vivo and ex vivo methods was the same.

In order to obtain a better estimate of the difference in water content determined by the two methods, PBV was added to the EVLW. A correlation was observed between the two measurements $(r=0.91)$. However, the thermodilution method showed a systematic overestimate of $3.5 \pm 2.3 \mathrm{~mL}$ in the EVLW measurements, as shown in Figure 1B. This is considered to be relevant since it might be necessary to correct EVLW from the in vivo value, adding an overestimation value, in newborns weighing less than $2700 \mathrm{~g}$.

\section{Analysis of hemodynamic results after MAS and administration of sildenafil}

The hemodynamic data showed that HR was significantly increased in the MAS group, whereas the other parameters (SAP, $\mathrm{CO}, \mathrm{Cl}$, and SVRI) were unchanged.

Table 1. Effect of meconium on circulating thoracic blood of newborn piglets (calculated parameters).

\begin{tabular}{lcc}
\hline & Basal & Meconium \\
\hline ITBV $(\mathrm{mL})$ & $30 \pm 10$ & $23 \pm 8^{*}$ \\
PBV $(\mathrm{mL})$ & $5.4 \pm 2$ & $1.4 \pm 0.3^{*}$ \\
GEDV $(\mathrm{mL})$ & $24 \pm 8$ & $19 \pm 7^{*}$ \\
\hline
\end{tabular}

Data are reported as means $\pm S D$ for $N=19$. ITBV = intra-thoracic blood volume; $\mathrm{PBV}=$ pulmonary blood volume; GEDV = global end-diastolic volume. ${ }^{*} \mathrm{P}<0.05$ compared to control (Student $t$-test). 

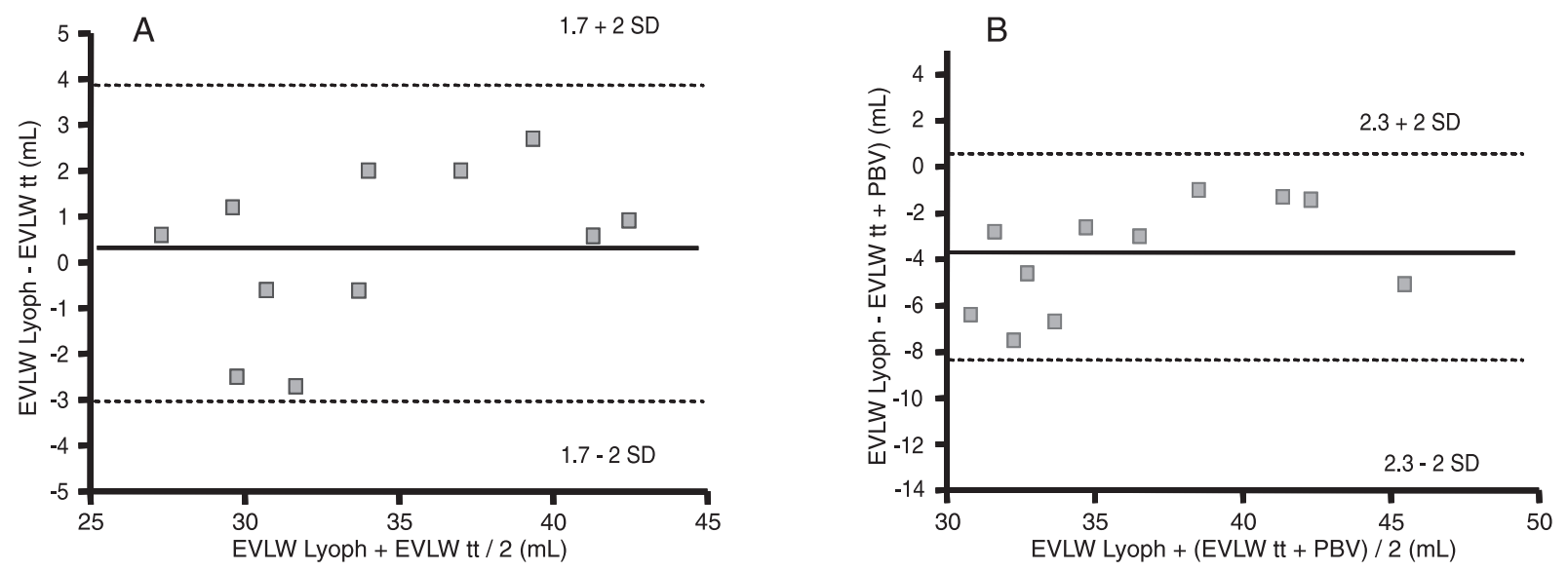

Figure 1. A, Bland-Altman analysis comparing EVLW measured by tt and LW determined by lyophylization (Lyoph). The abscissa shows the average of both measures and the ordinate shows the difference between ex vivo (LW) and in vivo (tt) assessment of lung water. Bias (LW - EVLW tt) was $0.3 \mathrm{~mL}$ (solid line); bias SD was $1.7 \mathrm{~mL}$ and the $95 \%$ confidence interval was -3.1 to $+3.8 \mathrm{~mL}$ (dotted line). B, Bland-Altman analysis comparing EVLW tt + PBV and LW ex vivo. The abscissa shows the mean of the two types of measurements and the ordinate shows the difference between the two methods. Bias (lyophilized-thermodilution values) was $-3.8 \mathrm{~mL}$ (solid line); bias SD was $2.3 \mathrm{~mL}$ and the $95 \%$ confidence interval was $-8.4 \mathrm{~mL}$ to $+0.69 \mathrm{~mL}$ (dotted line). EVLW = extravascular lung water; tt $=$ transcardiopulmonary thermodilution; LW = lung water; PBV = pulmonary blood volume.
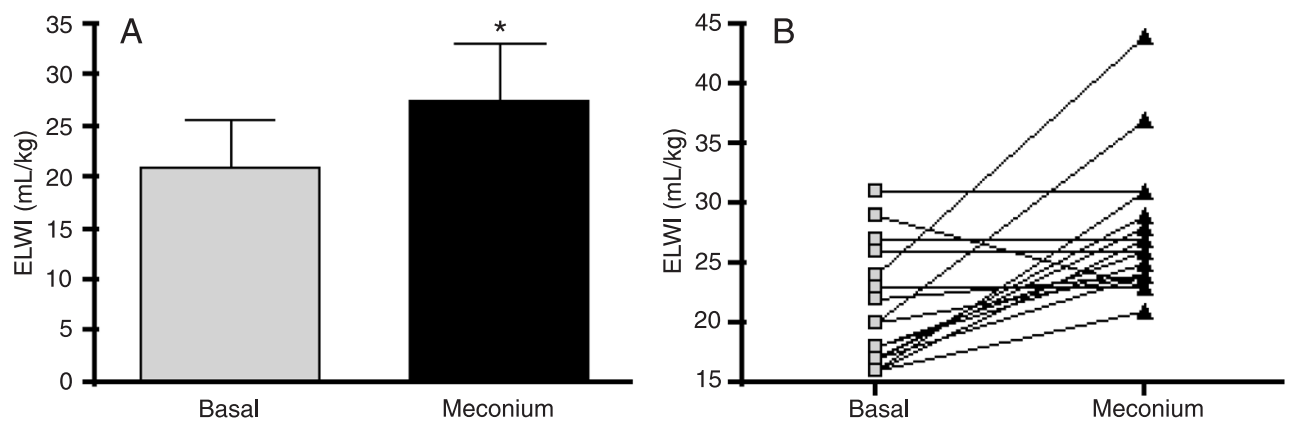

Figure 2. $A$, Modification of extravascular lung water indexed (ELWI) after meconium aspiration. Data are reported as means $\pm \mathrm{SD}$. $B$, Individual modification of ELWI, pre- and post-meconium. ${ }^{*} \mathrm{P}<0.001$ compared to basal (Student $t$-test).

Mean PAP significantly increased from $25 \pm 4$ to $40 \pm 6$ Torr with an increased PVRI of 3 Torr, as expected to occur in the most severe human cases of MAS.

The mean PAP increase was accompanied by a significant $\sim 9 \%$ decrease in $\mathrm{SatO}_{2}$, with a decrease in the $\mathrm{PO}_{2} /$ $\mathrm{FiO}_{2}$ ratio from $473 \pm 179$ to $124 \pm 92$ post-meconium $(\mathrm{P}<$ 0.01 ). It was necessary to modify the ventilation parameters in order to improve oxygenation: MIP (basal $18 \pm 2 \mathrm{cmH}_{2} \mathrm{O}$ $v s$ a post-meconium value of $24 \pm 2 \mathrm{cmH}_{2} \mathrm{O}$ ) and $\mathrm{RF}$ (basal $35 \pm 6$ vs a post-meconium value of $42 \pm 10 \mathrm{cycles} / \mathrm{min}$ ).

The parameters ITBV, GEDV and PBV showed a significant decrease after meconium administration (Table 1), indicating a decrease in circulating thoracic blood.

A significant increase in the in vivo mean of ELWI of 7
$\mathrm{mL} / \mathrm{kg}$ was detected by the simple thermodilution method (Figure 2A) after meconium instillation. In 5 of 19 cases, the ELWI did not increase, remaining the same or decreasing compared to the basal value (Figure 2B).

The VPI also increased significantly from a basal value of $7 \pm 3$ to a post-meconium value of $11 \pm 5 \mathrm{~mL}(P<0.01)$, showing that the permeability of the alveolocapillary membrane changed after meconium aspiration.

After administration of sildenafil, the increase in PAP was prevented, as shown in Figure 3, where basal PAP was $24.6 \pm 3 \mathrm{mmHg}$ and sildenafil PAP was $31 \pm 6.1 \mathrm{mmHg}$, with no differences between them, in contrast to a PAP value of $40.4 \pm 6.4 \mathrm{mmHg}$ for the meconium aspiration group. In addition, lung edema was also prevented by sildenafil 
administration before the development of the complete response to meconium in the airway, as demonstrated by the ELWI values shown in Figure 4.

\section{Histology of meconium-affected lungs}

Histological analysis of lungs after meconium aspiration revealed alveolocapillary and large vessel congestion (Figure 5B). Structural differences between control and meconium aspiration lungs can be observed in the microphotographs in Figure 5A. As indicated, interstitial alveolar and perivascular edema was observed. However, the most relevant feature was the presence of non-specific acute inflammatory elements in the interstitial space, such as polymorphonuclear neutrophils. This resulted in as nonspecific chemical pneumonitis due to the presence of meconium in the airway (Figure 5B).

\section{Discussion}

In the present study, newborn piglets were monitored in vivo after meconium aspiration. Both the hemodynamic profile and the changes in EVLW and in blood gas exchange were analyzed. A thermodilution device, validated here for the first time in small newborn piglets (under $2700 \mathrm{~g}$ ), was used to evaluate EVLW and other parameters. This methodology permits a complete evaluation and, although entailing the same risk as arterial catheterization, it results in the possibility of obtaining knowledge about the evolution of severe diseases, such as MAS. Furthermore, the availability of umbilical catheters to be used for humans when applying this methodology today enables the design of studies that go beyond experimental animal investigations.

\section{MAS model}

Airway aspiration of meconial amniotic fluid results in airway obstruction and alveolocapillary damage, leading to pulmonary ventilation-perfusion mismatch. After meconium aspiration, the initial airway obstruction is followed by an inflammatory reaction with neutrophils infiltrating lung tissues and an increase in pulmonary vascular resistance. One of the critical characteristics of this disorder is the establishment of PHT (13) as a result of hypoxia and the release of vasoactive compounds such as tromboxane $A_{2}$ (14) and endothelins (15). Pulmonary vasoconstriction occurs despite CO stability. The increase in PVRI and HR maintains the $\mathrm{CO}$, a characteristic of the newborn pulmonary circuit.

The intrapulmonary shunt and airway obstruction required the adjustment of the ventilatory parameters to preserve oxygenation, as previously reported by others (15). A significant increase in PAP as a consequence of hypoxemia was observed in $\sim 60 \%$ of the animals. The high percentage of affected animals proves the potential application of this model for the study of the pathophysiology of this disorder, considering that only $1 \%$ of human newborns develop severe

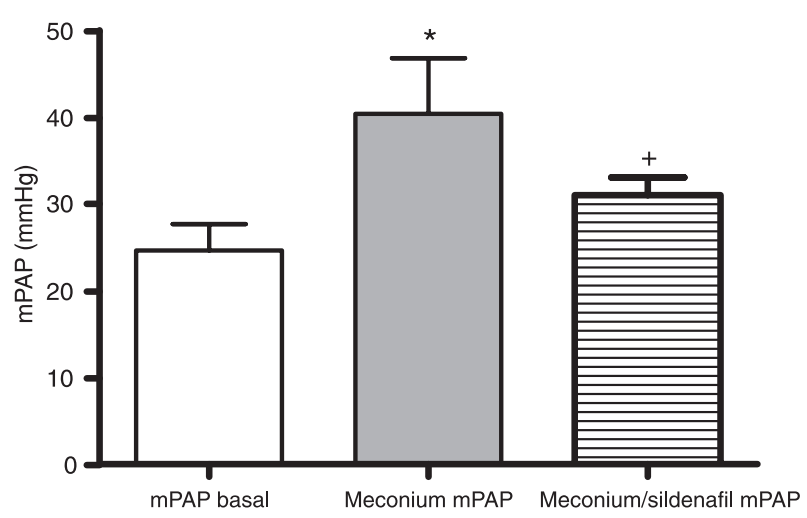

Figure 3. Mean pulmonary arterial pressure (mPAP) in three different situations: basal, after meconium aspiration and after meconium aspiration plus treatment with $2 \mathrm{mg} / \mathrm{kg}$ sildenafil. Data are reported as means $\pm S D$. Group comparisons demonstrated an increase in PAP when comparing meconium aspiration to basal data and prevention of the PAP increase after administration of sildenafil. ${ }^{*} P<0.001$ compared to basal; ${ }^{+} P<0.001$ compared to meconium (Student $t$-test).

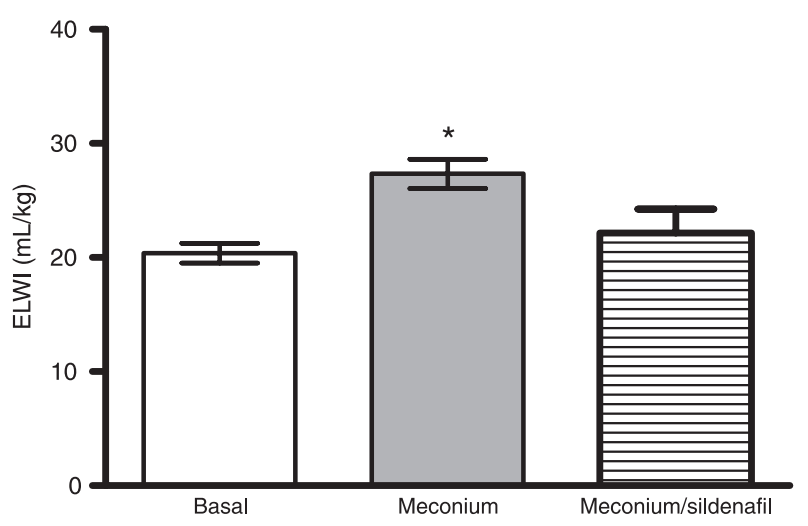

Figure 4. Extravascular lung water indexed (ELWI) under basal conditions, after meconium aspiration and after meconium aspiration plus treatment with $2 \mathrm{mg} / \mathrm{kg}$ sildenafil. Data are reported as means \pm SD. Preservation of the ELWI at low levels is observed when animals with meconium aspiration are treated with sildenafil, in contrast to animals receiving only meconium aspiration. ${ }^{*} P$ $<0.001$ compared to baseline (Student $t$-test).

PHT after MAS (16). However, PAP is increased over SAP in severely affected babies after MAS, which was not the case for the piglets studied here.

\section{MAS and pulmonary edema}

A disruption in the clearance of lung edema explains the increase in the amount of fluid in the interstitial and alveolar spaces (17). Classically, hydrostatic and osmotic forces are responsible for maintaining the alveolar space free of fluids (18). Recently, evidence has been reported for active ion transport across the alveolar epithelium, 

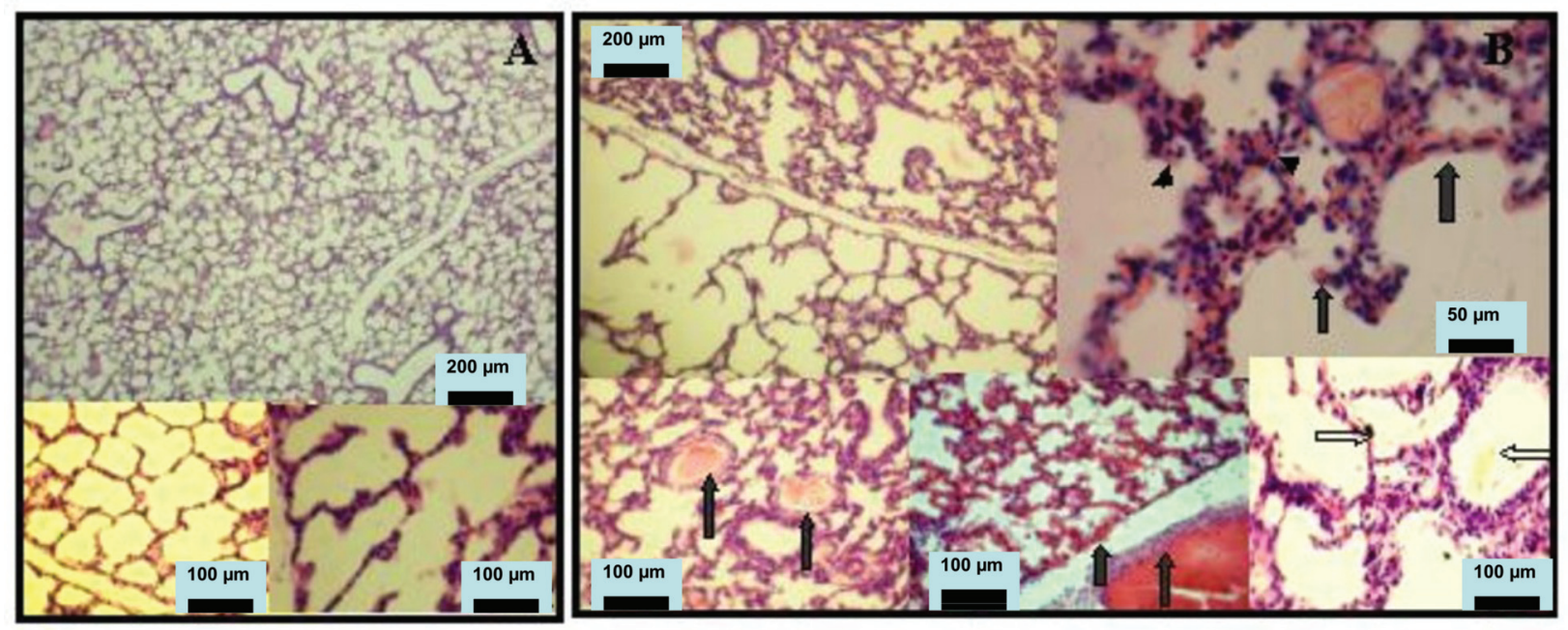

Figure 5. $A$, Sections of control lungs and, $B$, histological images after meconium instillation into the airway. Open arrows indicate vascular congestion or the presence of meconium in the alveolar lumen, and filled arrows indicate polymorphonuclear neutrophils and congestive vessels.

generating an osmotic gradient, which leads to water reabsorption (19). Other factors have been shown to affect active ion transport: $\mathrm{Na}^{+}-\mathrm{K}^{+}$ATPase stimulants including $\beta_{2}$ adrenergic agonists, growth factors, cytokines, and thyroid hormones promote fluid reabsorption. On the other hand, oxidants, serine proteases, hypoxia, and nitric oxide inhibit the re-absorption process (20). New regulating factors as well as transport proteins have recently been shown to be involved in this process (21).

\section{Methodological validation for the assessment of EVLW}

In vivo EVLW assessment is a useful tool for the diagnosis of pulmonary edema and can be used as a guide for administering fluids and drugs (22). Additionally, in vivo EVLW determination may allow the analysis of strategies to improve LW clearance $(21,23)$. The methodology used in the present study for the determination of EVLW proved to be more sensitive than chest radiographs or oxygenation indexes for the early detection of pulmonary edema (4-6), with the accuracy calculated by other investigators being around $90 \%$ (24). However, in the case of human babies it is impossible to determine the time of aspiration or the time it takes to develop PHT after MAS, a variability that must be taken into account. Quantitative determination of pulmonary edema is a useful and dynamic marker of severity and progression of the pathological condition. The thermodilution technique is simple and safe for patients, permitting repetitive measures (25). The availability of umbilical catheters opens the possibility of using it during the newborn period.

In the present study, the increase in EVLW was confirmed by single thermodilution after meconium aspiration in newborn piglets. This is the first report of EVLW determination by this method in animals weighing less than
$2700 \mathrm{~g}$. Since there is a good correlation with the ex vivo measurement of LW content, we conclude that the in vivo method is useful to determine EVLW in animals weighing 1300 to $2700 \mathrm{~g}$. When considering the PBV calculated by the monitor in the EVLW determination, the correlation remains significant $(r=0.89)$. Additionally, we demonstrated an overestimate of EVLW determined by single thermodilution $(3.5 \mathrm{~mL})$ compared to the gravimetric method. These results agree with previous reports that showed an overestimate of 2 to $4 \mathrm{~mL} / \mathrm{kg}(26-28)$. A possible reason is that the PiCCO software used is designed for adults with a higher GEDV, and perhaps the value should be corrected for newborns. In fact, this limitation affects only the absolute EVLW measurement, while the linear relationship between weight and EVLW is preserved (24). Some reports, which compared the gravimetric LW determination with single thermodilution (using bigger animals), indicated that both methodologies correlate with pulmonary edema and VPI increase $(4,26)$.

The decrease in PBV could be related to PHT with blood flow redistribution towards extrapulmonary areas. Although some reports have recommended pointing out pitfalls in EVLW thermodilution assessment when PHT occurs, the sensitivity of the method in this and other studies was adequate $(4,29)$.

Histological analysis revealed capillary vascular congestion and an increase in the interstitial fluid when compared to control lungs, as previously reported (17). Under physiological conditions, the fluid clearance mechanisms from the final stages of the gestational period leads to a decrease in the amount of LW (30).

The mean basal EVLW was increased when compared to other reports $(31,32)$. One of the reasons could be due to the age of the piglets (12 to $72 \mathrm{~h}$ ) in the present study. Recently, Krause et al. (10) reported EVLW values obtained 
by single thermodilution and by gravimetric assessment in 2- to 10-day-old piglets (weighing $2700 \pm 700 \mathrm{~g}$ ) after pulmonary edema induced by repeated airway lavages, although the basal EVLW values were not reported. Other species such as rabbits have higher mean EVLW values than piglets, with 4-day-old rabbits having $83 \%$ LW content compared to wet lung weight, higher than that observed in the present study (33). The increase in EVLW after meconium aspiration has been reported previously in pigs and human beings. Schiffmann et al. (7) observed $27.7 \pm 16.8$ $\mathrm{mL} / \mathrm{kg}$ EVLW in critically ill children aged 1 to 15 months. The lower variability observed in the present study (mean $\pm \mathrm{SD}, 20.8 \pm 4.8$ and $27.5 \pm 5.6 \mathrm{~mL} / \mathrm{kg}$, for the basal and meconium conditions, respectively) may be explained by the fact that there was only one etiology.

Other reports have shown an increase in EVLW determined by single thermodilution after acute lung injury in different species $(12,28)$, using mostly oleic acid to induce damage $(27,34,35)$. However, the MAS model reproduces the situation of human newborns with this disorder (3).

\section{Increase in EVLW}

The aspiration of meconium could directly injure the alveolocapillary membrane and induce a complementmediated inflammatory response (36). The inflammatory process recruits neutrophils, induces activation of alveolar macrophages (37) and triggers a cascade of events including release of cytokines, proteolytic enzymes and reactive oxygen species, which produce alveolocapillar damage, protein leakage into the alveolar space, and lung edema (36). According to other reports (38), the presence of leukocytes infiltrating lung tissue in histological analysis after meconium aspiration reveals the occurrence of pneumonitis. Increased vascular permeability and fluid movement towards the interstitial space associated with increased protein permeability are relevant in this pathologic process (38). The increase in VPI observed in vivo confirms the existence of vascular permeability changes, with VPI being considered to be a useful parameter in differentiating hydrostatic from vascular permeability edema (26).

\section{References}

1. Vain NE, Szyld EG, Prudent LM. Evidence based practice and the prevention and management of meconium aspiration syndrome. Eur J Pediatr 2005; 164: 789.

2. Finer NN. Surfactant use for neonatal lung injury: beyond respiratory distress syndrome. Paediatr Respir Rev 2004; 5 (Suppl A): S289-S297.

3. Dargaville PA, South M, McDougall PN. Surfactant and surfactant inhibitors in meconium aspiration syndrome. $J$ Pediatr 2001; 138: 113-115.

4. Nirmalan M, Niranjan M, Willard T, Edwards JD, Little RA, Dark PM. Estimation of errors in determining intrathoracic blood volume using thermal dilution in pigs with acute lung
Additionally, the increase in PAP may lead to the increase in EVLW (39) since the pulmonary vasoconstriction induces changes in the pulmonary capillary pressures, resulting in the passage of fluid into the extravascular space.

\section{Effect of early administration of sildenafil}

Sildenafil has been extensively studied for the treatment of established PHT and the information obtained has already been properly applied to clinical practice (40). However, the potential of sildenafil for the prevention of the deleterious effects of MAS has not been explored. In the present study, we confirmed the preventive capacity of sildenafil regarding the development of PHT and lung edema, two critical events in the pathology of PHT secondary to MAS. Moreover, our study reveals the possibility of monitoring the activity of sildenafil in vivo, suggesting a new potential application of the drug that should be studied in depth.

We conclude that, in newborn piglets smaller than $2700 \mathrm{~g}$, the establishment of experimental MAS can be monitored in vivo. Monitoring of pulmonary edema by single thermodilution is a reliable tool, in particular for the detection of real-time modifications of EVLW and CO, among others. Different therapeutic strategies to restore the physiological water content and to improve oxygenation could be evaluated.

\section{Acknowledgments}

Special thanks are due to "La Familia" farm for their continuous support with the experimental work. We are grateful to Prof. José Luis Díaz-Rossello and to the nursery staff of the University Hospital, Montevideo, for their constant help. We also wish to thank José Barreto for his continuous assistance with the experimental procedures. We are especially grateful to Prof. Sznajder, Northwestern University, Chicago, for his critical advice during the correction of this manuscript. Research partially supported by PROINBIO, School of Medicine, Montevideo, and CSIC, UdelaR, Montevideo. injury and haemorrhage. Br J Anaesth 2004; 93: 546-551.

5. Baudendistel L, Shields JB, Kaminski DL. Comparison of double indicator thermodilution measurements of extravascular lung water (EVLW) with radiographic estimation of lung water in trauma patients. J Trauma 1982; 22: 983-988.

6. Halperin BD, Feeley TW, Mihm FG, Chiles C, Guthaner DF, Blank NE. Evaluation of the portable chest roentgenogram for quantitating extravascular lung water in critically ill adults. Chest 1985; 88: 649-652.

7. Schiffmann H, Erdlenbruch B, Singer D, Singer S, Herting E, Hoeft A, et al. Assessment of cardiac output, intravascular volume status, and extravascular lung water by transpulmo- 
nary indicator dilution in critically ill neonates and infants. $J$ Cardiothorac Vasc Anesth 2002; 16: 592-597.

8. Baquero H, Soliz A, Neira F, Venegas ME, Sola A. Oral sildenafil in infants with persistent pulmonary hypertension of the newborn: a pilot randomized blinded study. Pediatrics 2006; 117: 1077-1083.

9. Steinhorn RH, Kinsella JP, Pierce C, Butrous G, Dilleen M, Oakes $M$, et al. Intravenous sildenafil in the treatment of neonates with persistent pulmonary hypertension. $J$ Pediatr 2009; 155: 841-847.

10. Krause MF, Wiemann T, Reisner A, Orlowska-Volk M, Kohler $H$, Ankermann T. Surfactant reduces extravascular lung water and invasion of polymorphonuclear leukocytes into the lung in a piglet model of airway lavage. Pulm Pharmacol Ther 2005; 18: 129-139.

11. Haworth SG, Hislop AA. Adaptation of the pulmonary circulation to extra-uterine life in the pig and its relevance to the human infant. Cardiovasc Res 1981; 15: 108-119.

12. Newman EV, Merrell M., Genecin A, Monge C, Milnor WR, McKeever WP. The dye dilution method for describing the central circulation. An analysis of factors shaping the timeconcentration curves. Circulation 1951; 4: 735-746.

13. Martell M, Blasina F, Silvera F, Tellechea S, Godoy C, Vaamonde $\mathrm{L}$, et al. Intratracheal sildenafil in the newborn with pulmonary hypertension. Pediatrics 2007; 119: 215-216.

14. Soukka H, Viinikka L, Kaapa P. Involvement of thromboxane A2 and prostacyclin in the early pulmonary hypertension after porcine meconium aspiration. Pediatr Res 1998; 44: 838-842.

15. Ku CY, Liao SL. Hypoxemia inducing endothelin-1 secretion in meconium aspiration in piglets. Acta Paediatr Taiwan 2001; 42: 340-344.

16. Ziadeh SM, Sunna E. Obstetric and perinatal outcome of pregnancies with term labour and meconium-stained amniotic fluid. Arch Gynecol Obstet 2000; 264: 84-87.

17. Martinez-Burnes J, Lopez A, Wright GM, Ireland WP, Wadowska DW, Dobbin GV. Ultrastructural changes in the lungs of neonatal rats intratracheally inoculated with meconium. Histol Histopathol 2003; 18: 1081-1094.

18. Staub NC. Pulmonary edema. Physiol Rev 1974; 54: 678811.

19. Mutlu GM, Sznajder JI. Mechanisms of pulmonary edema clearance. Am J Physiol Lung Cell Mol Physiol 2005; 289: L685-L695.

20. Quinn DA, Moufarrej RK, Volokhov A, Hales CA. Interactions of lung stretch, hyperoxia, and MIP-2 production in ventilator-induced lung injury. J Appl Physiol 2002; 93: 517525.

21. Olivera WG, Ridge KM, Sznajder JI. Lung liquid clearance and $\mathrm{Na}, \mathrm{K}-\mathrm{ATP}$ ase during acute hyperoxia and recovery in rats. Am J Respir Crit Care Med 1995; 152: 1229-1234.

22. Fernandez-Mondejar E, Guerrero-Lopez F, Colmenero M. How important is the measurement of extravascular lung water? Curr Opin Crit Care 2007; 13: 79-83.

23. Berthiaume Y, Folkesson HG, Matthay MA. Lung edema clearance: 20 years of progress: invited review: alveolar edema fluid clearance in the injured lung. J Appl Physiol 2002; 93: 2207-2213.

24. Fernandez-Mondejar E, Rivera-Fernandez R, Garcia-Delgado M, Touma A, Machado J, Chavero J. Small increases in extravascular lung water are accurately detected by trans- pulmonary thermodilution. J Trauma 2005; 59: 1420-1423.

25. Patroniti N, Bellani G, Maggioni E, Manfio A, Marcora B, Pesenti A. Measurement of pulmonary edema in patients with acute respiratory distress syndrome. Crit Care Med 2005; 33: 2547-2554.

26. Katzenelson R, Perel A, Berkenstadt H, Preisman S, Kogan $\mathrm{S}$, Sternik L, et al. Accuracy of transpulmonary thermodilution versus gravimetric measurement of extravascular lung water. Crit Care Med 2004; 32: 1550-1554.

27. Kirov MY, Kuzkov VV, Kuklin VN, Waerhaug K, Bjertnaes LJ. Extravascular lung water assessed by transpulmonary single thermodilution and postmortem gravimetry in sheep. Crit Care 2004; 8: R451-R458.

28. Rossi P, Wanecek M, Rudehill A, Konrad D, Weitzberg E, Oldner A. Comparison of a single indicator and gravimetric technique for estimation of extravascular lung water in endotoxemic pigs. Crit Care Med 2006; 34: 1437-1443.

29. Michard F, Schachtrupp A, Toens C. Factors influencing the estimation of extravascular lung water by transpulmonary thermodilution in critically ill patients. Crit Care Med 2005; 33: 1243-1247.

30. Bland RD. Lung fluid balance during development. NeoReviews 2005; 6: 255-267.

31. Lopez-Herce J, Ruperez M, Sanchez C, Garcia C, Garcia E. Estimation of the parameters of cardiac function and of blood volume by arterial thermodilution in an infant animal model. Paediatr Anaesth 2006; 16: 635-640.

32. Roch A, Michelet P, Lambert D, Delliaux S, Saby C, Perrin $G$, et al. Accuracy of the double indicator method for measurement of extravascular lung water depends on the type of acute lung injury. Crit Care Med 2004; 32: 811-817.

33. Sedin G, Bogner P, Berenyi E, Repa I, Nyul Z, Sulyok E. Lung water and proton magnetic resonance relaxation in preterm and term rabbit pups: their relation to tissue hyaluronan. Pediatr Res 2000; 48: 554-559.

34. Kuz'kov VV, Kirov MI, Waerhaug K, Mortinsen VN, Kuklin VN, Suborov EV, et al. [Assessment of current methods quantitating extravascular lung water and pulmonary aeration in inhomogeneous lung injury: an experimental study]. Anesteziol Reanimatol 2007; 4-9.

35. Neumann P. Extravascular lung water and intrathoracic blood volume: double versus single indicator dilution technique. Intensive Care Med 1999; 25: 216-219.

36. Korhonen K, Soukka H, Halkola L, Peuravuori H, Aho H, Pulkki K, et al. Meconium induces only localized inflammatory lung injury in piglets. Pediatr Res 2003; 54: 192-197.

37. Kojima T, Hattori K, Fujiwara T, Sasai-Takedatsu M, Kobayashi $Y$. Meconium-induced lung injury mediated by activation of alveolar macrophages. Life Sci 1994; 54: 15591562.

38. Tyler DC, Murphy J, Cheney FW. Mechanical and chemical damage to lung tissue caused by meconium aspiration. Pediatrics 1978; 62: 454-459.

39. Colmenero M, Perez Villares JM, Fernandez Sacristan MA, Garcia DM, Fernandez ME. Effect of pulmonary artery pressure on extravascular lung water in an experimental model of acute lung injury. Acta Anaesthesiol Scand 2005; 49: 1449-1455.

40. Spillers J. PPHN: is sildenafil the new nitric? A review of the literature. Adv Neonatal Care 2010; 10: 69-74. 